\title{
FABRICAÇÃO DE UM RESERVATÓRIO ERGONÔMICO PARA A PRODUÇÃO DE BIOFERTILIZANTES
}

Bruno Victor Delmondes de Moura, (UFCG), brunodemoura_@hotmail.com

Francisco Mendes dos Santos Júnior, (UFCG), junhor2012@hotmail.com

José Gustavo Alex Sales dos Santos, (UFCG), gustavo_alex234@hotmail.com

Laís Vaz Mendes, (UFCG), laisvvaz@gmail.com

Matheus Ferreira da Silva, (UFCG), mathf236@gmail.com

\section{Resumo}

A ergonomia pode aperfeiçoar consideravelmente a eficiência, produtividade e a prática de tarefas com mais conforto, segurança e saúde nos postos de trabalho. O trabalho realizado, consiste no desenvolvimento de uma fermenta com base nos conceitos de ergonomia e biomecânica. A ferramenta se torna importante por oferecer conforto ao colaborador, reduzir cansaço físico, dar condição para que o mesmo desempenhe sua função sem prejudicar sua saúde e evitar lesões por conta de má postura ou esforços repetitivos. O objetivo desse estudo é a elaboração de uma ferramenta para a melhoria do produto utilizado para produção de biofertiizantes na UFCG-CDSA, juntamente com a cooperação dos trabalhadores da área. Aplicando conceitos ergonômicos, chegou-se a um produto bem elaborado e pensado diante das necessidades dos mesmos.

Palavras-chave: Ergonomia, Biomecânica, Biofertilizantes.

\section{INTRODUÇÃO}

A associação internacional de ergonomia (IEA), estabeleceu no ano de 2000 uma definição sobre o que se trata a ergonomia. O termo ergonomia surge a partir do grego ergon, que significa " trabalho", e nomos que significa " leis ou normas". De acordo com a ABERGO (Associação Brasileira de Ergonomia), a ergonomia tem como propósito desenvolver e estabelecer técnicas de adequação do homem ao seu trabalho de forma eficaz e segura, promovendo mais conforto. 
A ergonomia tem como foco melhorar de forma eficaz o desempenho do indivíduo no seu posto de trabalho, desenvolver técnicas adaptativas para melhorar o modo em que as atividades diárias são exercidas, proporcionando maior qualidade de vida e buscando prevenir patologias que venham a surgir devido a esforços repetitivos e sem fundamentos, melhorando o rendimento e desenvolvendo ações que ofereceram benefícios para empresa e seus colaboradores.

A ergonomia, segundo Iida (2005), pode ser definida como sendo o estudo do relacionamento entre o homem e seu trabalho, equipamento, ambiente e particularmente, a aplicação dos conhecimentos de anatomia, fisiologia e psicologia na solução dos problemas que surgem desse relacionamento.

Trabalhos no meio agrícola oferecem um quadro de riscos ocupacionais que proporciona um conjunto de gravidade com graus variáveis. Dentre os trabalhos e processos que são praticados no campo o que apresentam maior risco ocupacional deste trabalho refere-se às posturas exercidas durante sua rotina de trabalho, algumas como uso inadequado de equipamentos, ferramentas, produtos químicos e até mesmo o próprio ambiente de trabalho.

As posturas estudadas diretamente pela ergonomia e pela segurança do trabalho costuma ser analisada levando em consideração o risco que pode causar a saúde do trabalhador, principalmente a carga física que é produzida em atributo dos esforços produzidos repetidamente pelos trabalhadores ao longo do seu serviço.

No meio agrícola, os trabalhadores geralmente realizam um conjunto de atividades que requer elevados esforços que compõem as ações cotidianas que e tratada no meio agrícola. As atividades que demandam grande esforços físicos como, longas caminhadas carregando grandes quantidades de peso, costumam acompanhar a vida dos agricultores desde a infância até a sua velhice. (MONTEIRO \& ADISSI, 2000).

Segundo Wisner (1987), as cargas do trabalho se definem como, física, mentais e psíquicas. A carga física é derivada do contato do corpo do trabalhador com sua atividade e seu meio de trabalho, onde se tem o esforço físico, posturas, umidade e a exposição a elevadas temperaturas. A carga mental é decorrente dos processos envolvendo tomada de decisão, a percepção de informação, memorização e demais. A carga psíquica pode ser 
referente aos efeitos negativos desencadeados ou feridos agravados pela atividade do trabalho.

A Associação Brasileira de Engenharia de Produção - ABEPRO - (2008) define a Engenharia do Produto como sendo um conjunto de ferramentas e processos, utilizados a fim de acompanhar todo ciclo de vida de um determinado produto, desde a ideia inicial até o lançamento do produto. Como subáreas da Engenharia do Produto, têm-se a gestão do desenvolvimento do produto, processos do desenvolvimento do produto e planejamento e projeto do produto (LEMES et al., 2010).

Diante do exposto, o presente trabalho visa a correção de transtornos musculares que viriam a ser prejudiciais ao trabalhador a longo prazo dessas atividades, através de um equipamento desenvolvido para facilitar e agilizar a produção, a partir da implementação de soluções cabíveis, beneficiando o trabalhador e evitando transtornos futuros.

\section{REFERENCIAL TEÓRICO}

\subsection{ERGONOMIA}

De acordo com Melatti (2014), a ergonomia é a ciência que busca a harmonização do posto de trabalho ao homem, onde as etapas são observadas e analisadas com a finalidade de encontrar algo que possa vir a dificultar a progressão do operador e assim, solucionar da melhor maneira possível a qualidade de vida e consequentemente aumentar a produtividade do indivíduo.

A ergonomia pode ser classificada em quatro fases, onde em cada uma, é visível a adaptação do posto que vai perdendo a força para a qualidade do processo, da organização e da qualidade de vida como um todo (HENDRICK, 1993).

$1^{\circ}$ fase, ergonomia de Hardware ou Tradicional:

A princípio os estudos eram voltados para as questões físicas do ser humano (capacidades e limites), em seguida com algumas mudanças, os estudos foram direcionados a questões físicas e fisiológicas e biomecânicas do ambiente de trabalho e na relação dos sistemas homem-máquina.

$2^{\circ}$ fase, ergonomia do Meio Ambiente: 
Refere-se a características ambientais naturais e artificiais (ruído, vibrações, temperatura, iluminação, aerodispersóides) que interferem no trabalho.

$3^{\circ}$ fase, ergonomia de Software ou Cognitiva:

Tem relação com o processamento de informações, voltada para a relação entre o homem e a máquina, que deixa de ser como na fase tradicional (antropométrica, biomecânica e fisiológica), e passa ter boa parte desse relacionamento intangível no campo físico, o operador não manuseia mais o produto, mas sim comanda uma máquina que está operando sobre o produto. A tecnologia da informação passa a ser uma extensão do cérebro e as interfaces para operação tem que levar em conta fatores cognitivos para facilitar o comando.

$4^{\circ}$ fase, macroergonomia:

Trata de questões mais amplas da ergonomia, expandindo a relação entre operador e máquina, atividade e ambiente, ela entra no contexto organizacional, psicossocial e político de um sistema. Diferencia-se das anteriores por priorizar o processo participativo envolvendo administração de recursos, trabalho em equipe, jornada e projeto de trabalho, cooperação e rompimento de paradigmas. O que garante intervenções ergonômicas com melhor resultado, reduzindo o índice de erros, e gerando maior aceitação e colaboração por parte das pessoas envolvidas.

\subsection{OBJETIVOS DA ERGONOMIA}

O interesse principal da ergonomia é melhorar a qualidade de vida do homem, que por sua vez, tende a ter uma melhor produtividade, atingindo melhores resultados qualitativos e quantitativos sobre as atividades realizadas. Cuidar do bem-estar do operador, significar cuidar do bem-estar da empresa, tendo em vista que $65 \%$ das patologias diagnosticas nos centros médicos, tem relação com o local de trabalho, dentre elas, temos as L.E.R. e o D.O.R.T.

- L.E.R (Lesão por Esforço Repetitivo)

É uma síndrome constituída por um grupo de doenças - tendinite, tenossinovite, bursite, epicondilite, síndrome do túnel do carpo, dedo em gatilho, síndrome do desfiladeiro 
torácico, síndrome do pronador redondo, mialgias -, que afeta músculos, nervos e tendões dos membros superiores principalmente, e sobrecarrega o sistema musculoesquelético. Esse distúrbio provoca dor e inflamação e pode alterar a capacidade funcional da região comprometida (VARELLA)

- D.O.R.T (Distúrbios Osteomusculares Relacionados ao Trabalho)

Os distúrbios osteomusculoligamentares relacionados ao trabalho, são um grupo heterogêneo de distúrbios funcionais ou orgânicos causados pela fadiga neuromuscular oriunda do trabalho realizado em uma posição fixa (trabalho estático) ou com movimentos repetitivos. Os sintomas são variados e iguais aos da L.E.R., dor, formigamento, dormência, choque, peso, fadiga, a diferença é que as D.O.R.T. tem origem comprovada em uma atividade profissional.

\subsection{ANTROPOMETRIA E A BIOMECÂNICA NA ERGONOMIA}

A antropologia é a ciência da humanidade com a preocupação de conhecer cientificamente o ser humano na sua totalidade (Marconi citado por SANTOS, 1997).

A antropometria é O estudo das dimensões e da partes do corpo humano, e uma das característica da ergonomia é a sua interdisciplinaridade, pois diversas áreas do conhecimento lhe dão sustentação, entre estas a antropometria, ciência que trata das medidas físicas do corpo humano tem uma importância especial, pois devido ao surgimento dos sistemas complexos de trabalho o conhecimento das dimensões físicas do homem com exatidão, é muito importante. Uma das aplicações das medidas antropométricas na ergonomia é no dimensionamento do espaço de trabalho e no desenvolvimento de produtos industrializados como mobília, automóveis, ferramentas, etc (AÑES, 2017).

Por sua vez, a biomecânica é o estudo da mecânica dos organismos vivos. Ou seja, em seu estudo as leis físicas da mecânica são aplicadas ao corpo humano, a fim de que se reduza as tensões nos músculos e articulações. Os princípios mais importantes da biomecânica para a Ergonomia são: 
- Manter as articulações em uma posição neutra;

- Conservar pesos próximos ao corpo;

- Evitar curvar-se para frente;

- Evitar inclinar a cabeça;

- Evitar torções de tronco;

- Evitar movimentos bruscos que produzam picos de tensão;

- Alternar posturas e movimentos;

- Restringir a duração do esforço muscular contínuo;

- Prevenir a exaustão muscular;

- Introduzir pausas curtas e frequentes.

\subsection{ERGONOMIA NA AGRICULTURA}

Boa parte dos trabalhadores rurais exercem suas funções em posições inadequadas ou forçadas, carregam peso além do normal e realizam movimentos rápidos e repetitivos, auxiliam para várias lesões e comprometendo a sua própria saúdeA elevação dos membros superiores e a rotação do tronco ao usar ferramentas manuais, por exemplo, podem ocasionar problemas nos ombros, como a síndrome do impacto.

Outra atividade que causa lesão do operador, e o levantamento manual de cargas pesadas sem nenhum equipamento, gerando assim muita carga sobre a coluna, gerando dores e problemas lombares. Pensando no bem-estar do trabalhador, já existem carrinhos para o transporte de insumos, que poupam os trabalhadores de carregarem sacos e outros tipos de peso de forma manual. Mas o problema está no preço que nem sempre é acessível para todos.

Outro tipo de mecanismo que auxilia no trabalho do campo, são os cabos para ferramentas manuais que distribuem o esforço gerado por toda a palma da mão, o que deixa o punho reto e reduz o cansaço nessa área. Já quando se trata do carregamento de cargas manuais, 
é possível utilizar os cintos ergonômicos para lombar, que dão mais rigidez ao tronco, corrigem a postura e previnem dores e lesões.

\subsection{ERGONOMIA DO PRODUTO}

A aplicação da ergonomia do produto baseia-se em três características desejáveis, e é necessário que todos estejam em equilíbrio. São elas: a técnica, que é a parte que faz o produto funcionar nos pontos de vista químico, mecânico, elétrico e eletrônico; a ergonômica, que consiste na garantia de que o produto possa interagir com o usuário; e a estética, que diz respeito ao design encarregado de proporcionar certo prazer para o consumidor.

Assim como deve ser levada em conta a usabilidade, uma vez que a qualidade do produto está ligada a ela, a usabilidade deve ser examinada acompanhando o uso do produto e a satisfação do usuário.

O estudo dos fatores ergonômicos no projeto de produto proporciona a melhor adequação do objeto aos seres vivos em geral, sobretudo no que diz respeito à segurança, ao conforto e à eficácia de uso ou de operacionalidade dos objetos, mas, particularmente, nas atividades e tarefas humanas (GOMES FILHO, 2003).

\section{METODOLOGIA}

Segundo Nascimento (2016), a presente pesquisa tem sua natureza aplicada, tendo em vista a geração de conhecimento a fim de solucionar problemas na pratica e em situação particular. A mesma pode ser apontada como explicativa, logo que emprega o método experimental e pratico buscando aproximação da própria realidade. Além de sua abordagem quantitativa, juntamente pelo emprego de medidas padronizadas e sistemáticas, facilitando assim a análise e comparação dos dados.

A investigação teve início no mês de março de 2019 na área experimental de manejo agroecológico, localizada na Universidade Federal de Campina Grande - UFCG, campus Sumé - PB, na qual foi realizada visitas para coleta de dados e análise das possíveis atuações no local, no qual foi observado uma grande dificuldade na fabricação de 
biofertilizantes, para o preparo do mesmo era utilizado um biodigestor caseiro no qual trazia inúmeros transtornos ergonômicos, tendo em vista todos estes empasses temos que o biodigestor caseiro foi o foco da investigação. A figura $X$ representa o fluxograma metodológico no qual demonstra as etapas da realização desta pesquisa.

\section{Figura 1 - Fluxograma Metodológico}

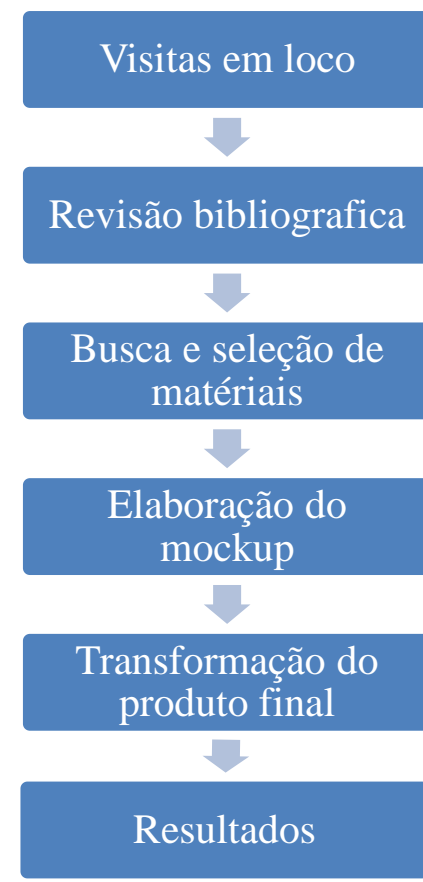

Fonte: Autores (2019)

A primeira etapa caracterizou-se pela visita e coleta de dados por meio da observação e comunicação com os operários do local, após a etapa primaria foi efetuado uma revisão bibliográfica com a intenção de estabelecer conceitos que serão tratados no projeto.

Na terceira etapa foi definida a busca e seleção dos matérias, os mesmos foram escolhidos mediante a capacidade de moldagem do ferro, a resistência do aço e alta gama de possibilidades da aplicação do cano de PVC.

O quarto processo baseou-se na elaboração do mockup, feito os testes do mesmo utilizando PVC e um balde de manteiga de $3 \mathrm{~kg}$, com os resultados foi possível constatar 
e prevenir as possíveis falhas de poderiam vir no produto final e assim proporcionar melhorias.

No processo de transformação, o tambor passou por algumas modificações tais elas como a implementação de um sistema a manivela de pvc, a fim de facilitar a mistura dos dejetos, uma peneira de base de ferro e a tela de aço e um sistema de escoamento do biofertilizante por meio de uma torneira fixada na base do tambor. Como resultado temos o produto finalizado e apto ao uso.

\section{RESULTADOS}

\subsection{PRODUTO FINAL}

O Produto Final, apresentado na Figura 2, consiste em um biodigestor caseiro, com capacidade de 200L, com sistema de filtragem e de mistura que dispõe de uma manivela de pás duplas e filtro de aço fixado a quatro barras de ferro e acoplado ao interior do recipiente, além de uma torneira plástica, para saída do biofertilizante.

Figura 2 - Produto Final obtido após testes de mock-up e melhorias ergonômicas.

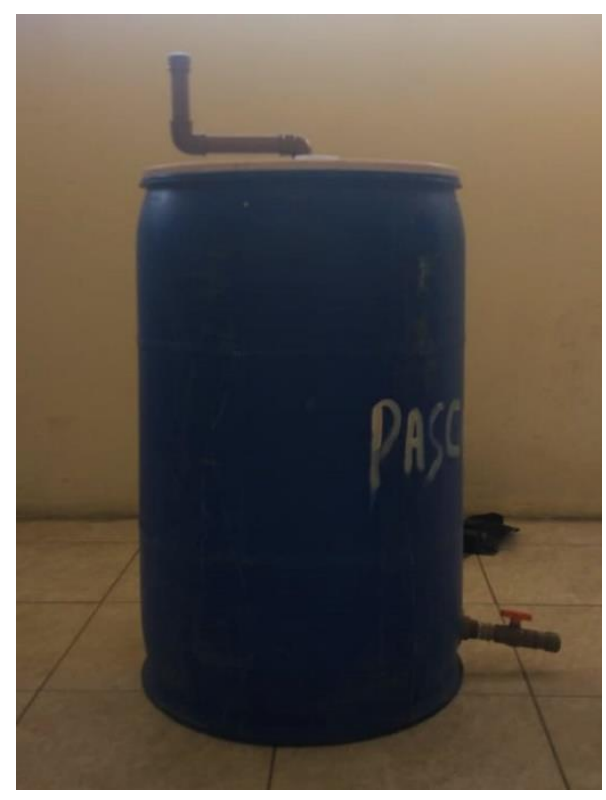

Fonte: Autores (2019)

Figura 3 - Sistema de filtragem 


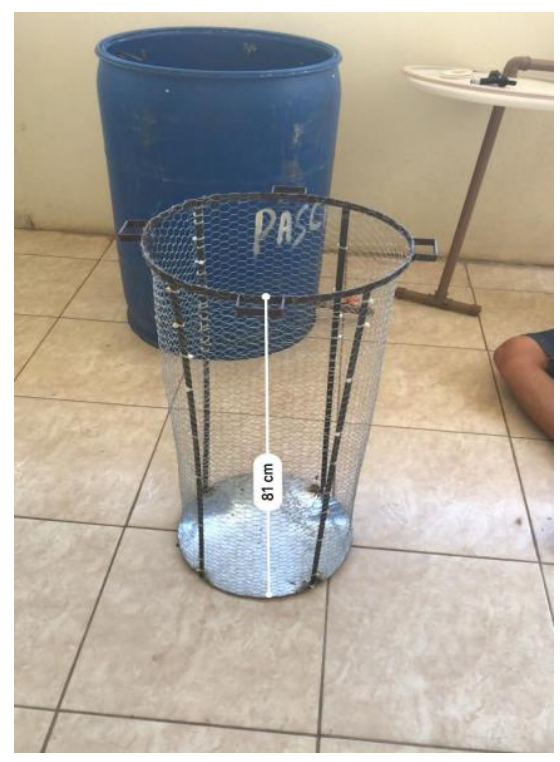

Fonte: Autores (2019)

Especificações básicas:

- Bombona plástica - 200L;

- Misturador e manivela: $3 \mathrm{~m}$ de cano PVC (32mm), 2 tampões (32mm), 2 joelhos (32mm), 1 "tê" (32mm), 2 tampões (32mm), 1 luva (32mm),

- Saída do sistema - torneira plástica $20 \mathrm{~mm}$;

- Filtro de aço - 1,5m de tela tipo mosqueteiro;

- Suporte do filtro de aço - 4 barras de aço de $1,25 \mathrm{~m}$;

- Base inferior - $1 \mathrm{~m}^{2}$ de chapa de ferro.

O produto final teve, como custo total de produção, o valor equivalente de $\mathrm{R} \$ 150$, incluindo a mão-de-obra terceirizada.

\subsection{PROCESSO DE FABRICAÇÃO}

Inicialmente, foram obtidas as medidas da bombona plástica, a fim de produzir as peças utilizadas durante a produção do reservatório. As barras de ferro foram soldadas juntamente à base inferior no fundo do reservatório e, em seguida, fora adicionada a tela filtrante.

Em seguida, foi produzida a manivela e o misturador, a partir da junção das frações de cano, por meio das conexões. Após isso, foi feita um orifício na tampa da bombona, para acoplagem da manivela, e outro na parte inferior do reservatório, para acoplagem da torneira de saída. 


\section{CONSIDERAÇÕES FINAIS}

A partir da identificação das necessidades dos usuários da ferramenta, a fabricação dos componentes do reservatório ergonômico atendeu as deficiências do produto, facilitando a extração do biofertilizante, e a limpeza do recipiente.

Com isso, houve um aperfeiçoamento no posto de trabalho do utilizador, otimizando seus movimentos, tornando-os mais produtivo e avançando os padrões convencionais dos métodos de trabalho na produção de biofertilizantes.

Com base na análise dos resultados obtidos, podem-se identificar novas oportunidades de melhoria do produto. Como perspectivas futuras, tem-se a readaptação do sistema, com o desenvolvimento de outro modelo de misturador, com três ou quatro pás, afim de facilitar a mistura do material, a fim de promover uma contínua melhoria no mesmo.

\section{REFERÊNCIAS}

AÑES, Ciro Romelio Rodriguez. ANTROPOMETRIA NA ERGONOMIA. 2017. Disponível em: < http://www.profala.com/artto20.pdf> Acesso: 29 Jan. 2020.

BLANCO, Oliver. Biofertilizantes: Preparados fermentados a base de merda de vaca. 2014.

<http://oextensionista.blogspot.com/2014/06/biofertilizantes.html\#.XR0ajehKjIU>. Acesso em 22 de jun. de 2019.

Blog BeL, ergonomia na agricultura: entenda a importância desse cuidado. 2019. Disponível em: < https://blog.belagro.com.br/ergonomia-na-agricultura-entenda-aimportancia-desse-cuidado/> Acesso: 29 Jan. 2020.

CERQUEIRA, Carlos Gonçalves.; HERMOSILlA, José Luís Garcia.; SILVA, Ethel Cristina Chiari da.; PIRATELLI, Cláudio Luiz.; JÚNIOR, Walther Azzolini. O desenvolvimento do produto sob a ótica ergonômica: uma contribuição à responsabilidade social da instituição e à formação interdisciplinar do discente. VI Congresso nacional de excelência em gestão, Niterói - RJ, 5 a 7 de agosto de 2010. 
CHENG, Lin Chih; MELO FILHO, Leonel Del Rey de. QFD: desdobramento da função qualidade na gestão de desenvolvimento de produtos. Belo Horizonte: Edgard Blucher, 2007. 568 p.

CHIAVENATO, Idalberto. Gestão de pessoas. 3ed. Rio de Janeiro: Elsevier, 2005.

$\begin{array}{llll}\text { Ergnomia } & \text { aplicada. } & \text { Disponível em: }<\end{array}$ http://ergonomiaaplicada.blogspot.com/2007/09/biomecnica-auxiliandoergonomia.html> Acesso: 29 Jan. 2020.

FERNANDES, André Luis Teixeira; TESTEZLAF, Roberto. Fertirrigação na cultura do melão em ambiente protegido, utilizando-se fertilizantes organominerais e químicos. Revista Brasileira de Engenharia Agrícola e Ambiental, v. 6, n.1, p. 45-50, 2002.

FREIRE, Bianca Cristina Abreu. Análise de fatores ergonômicos na atividade agrícola de uma empresa na contribuição da prevenção de acidentes e redução de riscos profissionais. Monografia (Aperfeiçoamento/Especialização em Ergonomia, Saúde e Segurança no Trabalho) - Universidade Federal dos Vales do Jequitinhonha e Mucuri, Teofilo Otoni - MG, 2008.

GOMES FILHO, João. Sistema Técnico de Leitura Ergonômica. 2ed. São Paulo: Escrituras, 2003.

IIDA, Itiro. Ergonomia: projeto e produção. São Paulo: Edgard Blücher, 2005.

LEMES, Isabela Korczovei.; TOSONI, Lorena Aparecida.; TRENTIN, Lorena Saviani.; SANTOS, Karla Aparecida.; TSUJIGUCHI, Lucas Tharcízio de Abreu. A área de Engenharia de Produto: apresentação de definições e conceitos e discussões do mercado de trabalho. IV Encontro de Engenharia de Produção Agroindustrial. 17 a 19 de novembro de 2010, FECILCAM, Campo Mourão - PR, 2010.

MENDES, René. Patologia do trabalho. 2ed. São Paulo: Atheneu, 2003.

MELATTI, juliana. Infoescola, navegando e aprendendo. 2014. Disponível em: <https://www.infoescola.com/saude/ergonomia/> Acesso: 28 Jan. 2020. 
Marelli, o ambiente motiva. 2015. Disponível em: <https://www.marelli.com.br/ergonomia> Acesso: 28 Jan. 2020.

MONTEIRO, Rosemary Araújo; ADISSI, Paulo José. Análise dos riscos ergonômicos da atividade de aplicação manual de herbicida. Programa Regional de Pós-graduação em desenvolvimento do Meio Ambiente/ UFPB. Seminário Internacional / João Pessoa 27 e 28 / julho/ 2000. (CD).

NASCIMENTO, F. P. Classificação da Pesquisa. Natureza, método ou abordagem metodológica, objetivos e procedimentos. 2016.

O que é Ergonomia. Associação Brasileira de Ergonomia. Disponível em: <http://www.abergo.org.br/internas.php?pg=o_que_e_ergonomia> Acesso em: 04 de fev. de 2020.

ProLife. AET - Análise Ergonômica do Trabalho. Disponível em: https://prolifeengenharia.com.br/servicos/aet-analise-ergonomica-do-trabalho/. Acesso em: 22/junho/2019.

SANTOS, Ana Cláudia Vera dos. Biofertilizante líquido, o defensivo da natureza. 2ed. Niteroi: Emater - Rio. Agropecuária fluminense, 8. 1992. 16p.

STUCHI, Júlia Franco. Biofertilizante: um adubo líquido de qualidade que você pode fazer. Brasília - DF, Embrapa, 2015.

SOUSA, F. L. L. Metodologia da Pesquisa Científica: teoria e prática - como elaborar TCC. Brasilia: Thesaurus, 2016. Cap. 6, p. 11. Disponível em: $<$ http://franciscopaulo.com.br/arquivos/Classifica\%C3\%A7\%C3\%A3o\%20da\%20Pesq uisa.pdf>. Acesso em: 21 jan. 2020.

TIMM, P. J.; GOMES, J. C. C.; MORSELLI, T. B. Insumos para agroecologia: Pesquisa em vermicompostagem e produção de biofertilizantes líquidos. Revista Ciência \& Ambiente, julho/dezembro, 2004.

VARELLA, Drauzio. Uol, DRAUZIO. Disponível em:< https://drauziovarella.uol.com.br/doencas-e-sintomas/lesao-por-esforco-repetitivo-lerdort/> Acesso: 28 Jan. 2020. 
